\title{
EL MÉTODO LEADER COMO POLITICADE DESARROLLO RURAL EN EXTREMADURA EN LOS ÚLTIMOS 20 AÑOS (1991-2013)
}

\author{
Ana Nieto Masot \\ Gema Cárdenas Alonso \\ Departamento de Arte y Ciencias del Territorio Universidad de Extremadura \\ ananieto@unex.es; gemacardenas@unex.ex
}

\section{RESUMEN}

Con el objetivo de activar el desarrollo de las áreas rurales europeas, y en concreto las de Extremadura, y reducir en lo posible sus diferencias socioeconómicas respecto a las zonas urbanas, desde los años 90 hasta la actualidad se han implantado en el medio rural europeo estrategias de desarrollo denominadas Método LEADER (Iniciativas LEADER y los ya extinguidos Programas Operativo PRODER implantados sólo en el territorio español). En este trabajo se pretende llevar a cabo el estudio de la implantación de esta metodología en el territorio extremeño, observando su evolución y presentando distintos resultados cualitativos y cuantitativos y comprobando si han contribuido en la reducción de las diferencias demográficas y socioeconómicas entre estos espacios rurales y las zonas urbanas, objetivo primordial de estas políticas europeas.

Palabras clave: LEADER, PRODER, FEADER, Desarrollo Rural.

\section{ABSTRACT}

From the 90s to the present day, Rural Policies called LEADER Method have been put in place in the European rural areas (Initiatives LEADER and PRODER are also included). Its objective is to activate the development in rural areas, in particular the rural areas of Extremadura, and to reduce as much as possible their socioeconomic differences in urban

Fecha de recepción: septiembre 2013.

Fecha de aceptación: julio 2014. 
areas. In this study, it aims to study the implementation of this LEADER Method in the territory of Extremadura, observing the evolution and showing different qualitative and quantitative results and checking if the Rural Policies have contributed to reduce demographic and socioeconomic differences between rural and urban areas, the main objective of these policies.

Keywords: LEADER, PRODER, FEADER, Rural Development.

\section{INTRODUCCIÓN}

Hasta el Acta Única Europea (1986) no se comienza a hablar, aunque todavía no profundamente, del medio y del desarrollo rural, concretándose la relación entre ambos conceptos en 1988 en el documento «El Futuro del Mundo Rural», en donde queda plasmada la realidad de este medio, con excedentes agrarios, paro, emigración, bajos niveles de renta y debilidad de sus sistemas productivos. De este modo, con el fin de mejorar sus condiciones y reducir las diferencias existentes con las zonas urbanas, desde los años 90 hasta la actualidad, se han implantado estrategias de desarrollo que denominaremos Método LEADER, por incluir las distintas Iniciativas LEADER y los ya extinguidos Programas PRODER implantados sólo en el territorio español.

Es un modelo de desarrollo rural integrado, endógeno e innovador, gestionado por Grupos de Acción Local, en aquellos territorios donde se experimentan los mayores desequilibrios demográficos y socioeconómicos. Su objetivo primordial es la diversificación de las actividades económicas, sobre todo aquellas que utilicen los recursos endógenos, mediante la puesta en marcha de una serie de proyectos cofinanciados por los fondos estructurales europeos, administraciones nacionales y agentes privados (Nieto y Gurría, 2010). Existen, por ello, tres elementos a destacar en la implementación del Método LEADER:1) el territorio o área LEADER, 2) una estrategia de desarrollo económico integral aprovechando sus recursos endógenos y acciones innovadoras y 3) el Grupo de Acción Local caracterizado por la financiación descentralizada, la cooperación y la colaboración entre agentes públicos y privados (OCDE, 2004).

En los últimos años han sido diversos los autores que han realizado estudios de estas políticas en diferentes regiones, tales como Márquez (1999), Ruíz et al (2000), Esparcia (2004), González (2006), Pillet (2008), Cejudo y Navarro (2009) y Papadopoulou et al (2011). Sus análisis presentan distintos puntos de vista, pero centrados mayoritariamente en la distribución de las inversiones, medidas, tipos de promotores, creación y mejora de empleo, nuevos alojamientos turísticos, incorporación de jóvenes y mujeres al mercado laboral, así como la diversificación económica en las áreas de estudio. Otros trabajos como Márquez et al (2005), Mondéjar et al (2007), Noguera et al (2009) y Navarro et al (2012), se han centrado, sobre todo, en la creación de indicadores relevantes que nos puedan servir para analizar el impacto y desarrollo de estas políticas y poder tener instrumentos objetivos de evaluación de dichos programas, tal y como exige la Comisión Europea, que puedan ser aplicados en todos los territorios LEADER. Por último, trabajos de autores como Dargan y Shucksmith (2008), Dax et al (2013) y Esparcia (2014), han 
realizado sus estudios centrándose en el papel de los actores públicos y privados en el desarrollo de sus territorios a través de la innovación, uno de los principales objetivos las distintas etapas de LEADER.

En este artículo se pretende llevar a cabo el estudio de las estrategias de Desarrollo Rural, LEADER y PRODER en etapas ya finalizadas (1991-2006), así como en el actual periodo de programación, 2007-2013 en Extremadura, observando su evolución (territorial, legislativa y sectores que han financiado), presentando distintos resultados y su implantación en el territorio. Se ha realizado este trabajo con los datos facilitados por el Gobierno de Extremadura y Redex (Red Extremeña de Desarrollo Rural) hasta septiembre de 2012, aun no estando disponibles oficialmente los relativos al último período de programación 2007-2013 por no estar justificados definitivamente sus presupuestos económicos.

Extremadura, a pesar de contar con un importante legado histórico, así como natural y cultural, presenta unas características poblacionales, territoriales y económicas que la han situado con un importante retraso socioeconómico respecto a otras regiones españolas y europeas. Características demográficas: poco más de un millón de habitantes tras décadas de sufrir una extensa emigración; territoriales: no tanto por sus más de $40.000 \mathrm{Km}^{2}$ de superficie, sino por las largas distancias entre sus extremos, con más de $300 \mathrm{Km}$. de norte a sur y más de 250 de este a oeste y una densidad media de 27 habitantes $/ \mathrm{km}^{2}$ y, económicas: el sector agrario tiene aún un peso determinante en su economía con una participación del $10 \%$ en el empleo regional y del $8 \%$ en el Valor Añadido Bruto (Nieto y Gurría, 2008). Además, su PIB se encuentra por debajo del $75 \%$ de la media europea, perteneciendo, por lo tanto, al grupo de regiones Objetivo Convergencia (antiguas Objetivo 1) y siendo receptora de diversas ayudas europeas al desarrollo como los Programas Operativos de los Fondos FEDER, FSE, FEOGA, Iniciativas LEADER,URBAN, EQUAL o los Fondos de Cohesión a nivel nacional.

En Extremadura, para la delimitación de las Iniciativas LEADER se ha considerado todo su territorio «rural» exceptuando los cuatro municipios de mayor población que presentan características urbanas y que son Badajoz, Cáceres, Mérida y Plasencia. Dentro de estos espacios rurales, y siguiendo la metodología del Instituto Nacional de Estadística, el 29,1\% de su población se concentra en 287 municipios, todos ellos con menos de 2.000 habitantes (zonas rurales), el 45,0 \% de la población en 84 municipios, con una población entre 2.000 y 10.000 habitantes (zonas intermedias), y un 25,8 \% en zonas urbanas (municipios con más de 10.000 habitantes, no llegando a superar en ningún caso más de 40.000 habitantes y siendo sólo el caso de 10 de ellos). Es por ello, una región que presenta un poblamiento muy disperso y concentrado principalmente en los grandes núcleos, coincidentes con las zonas agrarias más productivas (regadíos del Árrago-Alagón-Ambroz y Tiétar-Campo Arañuelo y el eje de las Vegas del Guadiana-Tierra de Barros) y localizados alrededor de las principales vías de comunicación (Autovía A-5 y Autovía Vía de la Plata) donde se localizan las mayores oportunidades de empleo, infraestructuras, equipamientos y servicios, así como las mayores rentas. En el resto del territorio nos encontramos con vacíos demográficos, con núcleos muy ruralizados y poco desarrollados económicamente y con características demográficas regresivas. Comprobaremos cómo la actuación e impacto de los Grupos LEADER no será homogénea y estará muy relacionada con la localización de los mismos en las zonas anteriormente descritas. 
Nos planteamos en este trabajo, el análisis de LEADER en Extremadura, por el valor que está adquiriendo en el desarrollo socioeconómico de las zonas rurales y por la novedad de introducir otras metodologías de gestión de ayudas públicas, políticas descentralizadas («bottom - up») y ejecutadas por la población autóctona a través de los Grupos de Acción Local. Además, Extremadura es un buen ejemplo de la práctica de estas Iniciativas como menciona la OCDE en su Informe de casos de estudio de Políticas de Desarrollo Rural (OCDE, 2004; González, 2006) y añadimos la mención que incorpora la Iniciativa LEADER + en su Reglamento (DOCE, (2000/C 139/05)) incidiendo en que sus acciones sean transferibles y con efecto demostrativo y puestas en conocimiento de la sociedad a través de estudios como éste donde podemos enseñar los resultados óptimos en determinadas zonas rurales.

Otro aspecto a destacar son los escasos trabajos de investigación que existen sobre esta temática en Extremadura, Nieto y Gurría $(2008$, 2010) donde se analizan estas inversiones hasta el año 2006 y, Márquez, 1999, estudiando estas Iniciativas en el sector turístico, añadiendo que se han introducido los datos del actual período de programación, FEADER y que cerrará sus convocatorias de proyectos a 31 de diciembre del 2013.

Por ello, nuestro trabajo se ha estructurado en tres grandes epígrafes: en el primero, definimos el Método LEADER centrándonos sobre todo en el desarrollo del FEADER y haciendo referencia a estudios previos donde ya se ha analizado la implantación de LEADER en etapas anteriores; en el segundo analizamos la implantación económica desde el año 1994 cuando ya ocupa el $80 \%$ del territorio extremeño hasta los últimos datos disponibles del FEADER (septiembre del 2012) ${ }^{1}$ y un último y tercer bloque donde se han introducido una serie de indicadores para comprobar los resultados de estas inversiones en los distintos Grupos de Acción Local.

\section{EL MÉTODO LEADER}

En 1991 surge la Iniciativa de Desarrollo Rural LEADER, cuya finalidad era llevar a cabo estrategias de desarrollo rural y local integrado. Así, todas las zonas europeas Objetivo 1 y Objetivo 5b pudieron optar a la misma, entre ellas Extremadura. Aparece para implantar programas de desarrollo rural desde el propio territorio y bajo el impulso y participación de la propia población, actuando sobre ámbitos comarcales en las zonas rurales que presentaban los mayores problemas de desarrollo socioeconómico, especial despoblamiento, envejecimiento y bajo nivel de rentas, y gestionándose por Grupos de Acción Local (GAL), una asociación de interlocutores públicos y privados de la comarca en cuestión. Con estas políticas se pretende la consecución de descentralizar la gestión del desarrollo rural (proceso de desarrollo «bottom -up», de abajo a arriba). En Extremadura, se concedieron a cuatro grupos localizados en áreas de las más deprimidas de la región (zonas de montaña y penillanura) y sometidas a una persistente emigración y abandono desde décadas previas (Nieto y Gurría, 2008).

1 Inversiones comprometidas a 30 de septiembre del 2012 procesadas por los Grupos de Acción Local y aprobadas por la Consejería de Agricultura y Desarrollo Rural del Gobierno de Extremadura. 
En los años siguientes se aprueban y ponen en marcha dos Iniciativas Europeas de Desarrollo Rural más, LEADER II (1995-1999) y LEADER + (2000-2006), con nuevos objetivos y planteamientos. LEADER I fue una experiencia pionera con la que se inició una metodología basada en la diversificación de las actividades en el mundo rural y con LEADER II se luchó por conseguirla a través de acciones innovadoras y la cooperación entre territorios, mientras que LEADER + enfatiza en la «necesidad de reflexionar sobre las potencialidades del territorio con una perspectiva a más largo plazo (...) y se apoye en las formas de valorización del patrimonio natural y cultural, en la creación de empleo y en la capacidad organizativa en las comunidades rurales» (Sancho, 1999).

Todo esto en el marco de la cofinanciación de una seria de medidas entre los Fondos Estructurales (FEDER, FEOGA-O, FSE, y actualmente FEADER), las administraciones y la participación privada, dentro de un Programa de Desarrollo Rural que posibilitará la ejecución tanto de proyectos productivos (con rentabilidad económica, como alojamientos de turismo rural, agroindustria o comercialización de productos locales) como no productivos (rehabilitación de patrimonio urbano, natural, mejora de accesos, difusión turística de comarcas o formación de trabajadores) dentro del diseño de una estrategia económica de comarca. Los Grupos de Acción Local serán los encargados de gestionar estos Fondos, decidirán qué proyectos se financiarán y estarán formados por una representación de las entidades públicas y de los agentes económicos y sociales de cada territorio, tanto en su Asamblea General como en su Junta Directiva y con una participación máxima del $50 \%$ de los agentes públicos en ambas (Nieto y Gurría, 2010).

La respuesta del mundo rural para acogerse a dicha Iniciativa fue tal que la capacidad financiera de las distintas autoridades nacionales y europeas fue insuficiente. Es por ello que, en 1996, la Comisión Europea aprueba el «Programa Operativo para el Desarrollo y Diversificación Económica de Zonas Rurales» (PRODER) al gobierno español para que pudieran gestionarlo Grupos que no habían accedido a la financiación de LEADER II. Funcionaba bajo los mismos principios y modelos de gestión, pero sin exigir un carácter innovador ni la cooperación transnacional en la concesión de proyectos, además de no recibir financiación del FSE para Formación y Empleo. Posteriormente en el año 2000, se aprueba la segunda edición de este programa con PRODER II (2000-2006) donde ya se podían incluir proyectos de cooperación y de formación y empleo por recibir toda la financiación de los Fondos Estructurales del FEOGA-O.

La ejecución territorial en estos 12 años (1994-2006) supuso la creación de 24 GAL que englobaron a 379 municipios, con $37.228 \mathrm{Km}^{2}$ y 761.157 habitantes (70,9\% del total regional) y es necesario destacar uno de los planteamientos conseguidos con estas actuaciones: la aplicación de una estrategia de desarrollo bajo un enfoque territorial, definiendo un área de actuación teniendo en cuenta sus características demográficas, socioeconómicas y culturales, sus necesidades, sus debilidades y sus potencialidades y creando con ello, además, una identidad territorial.

\section{EL FEADER, PERIÓDO DE PROGRAMACIÓN 2007-2013}

En este epígrafe nos vamos a centrar en el estudio del período actual de programación de la Política Europea de Desarrollo Rural con las ayudas del FEADER (2007-2013). Las nor- 
mativas de funcionamiento de los períodos anteriores pueden consultarse con más detalle en Nieto y Gurría $(2008,2010)$. Analizando las últimas reformas de la Política Agraria Común y los Reglamentos de los nuevos Fondos: FEAGA (Fondo Europeo Agrícola de Garantía) que sustituye a la Sección Garantía del FEOGA, y FEADER (Fondo Europeo Agrícola de Desarrollo Rural), que sustituye a la Sección Orientación del FEOGA, queda constancia de la inexistencia de una política de Desarrollo Rural como tal, ésta se sigue entendiendo como un complemento de la primera, cuyos principales soportes son la política de mercados y la contribución de las rentas. Siguen teniendo las mayores partidas presupuestarias el FEAGA para las ayudas directas a la producción agraria y solamente se ha conseguido un leve incremento en la financiación de las políticas de desarrollo rural del FEADER con respecto a etapas anteriores. El objetivo primordial de estos Fondos es mantener a la población en los núcleos rurales para fortalecer la competitividad de las explotaciones agrarias y facilitar alternativas a la actividad agropecuaria, de manera que se asegure, a la vez, una gestión eficaz del territorio basada en el respeto al medio ambiente, para lo cual se ha dotado al FEADER de unos importes que completan a los establecidos en el FEAGA para el sostenimiento de las rentas y la regulación de los mercados.

Con el Reglamento (CE) $n^{\circ}$ 1698/2005 del Consejo de 20 de septiembre de 2005, se establecen las normas generales para regular la ayuda comunitaria al desarrollo rural en el período 2007-2013, se definen los objetivos a los que debe contribuir y se establecen las normas relativas a la cooperación, programación, evaluación, gestión financiera, seguimiento y control en su ejecución basadas además en las responsabilidades que comparten los Estados miembros y la Comisión por estar enmarcadas dentro de Programas Nacionales de Desarrollo Rural, aspecto novedoso porque en anteriores períodos funcionaron como Iniciativas a escala europea y no incluidas en un Programa Nacional.

Estos objetivos se aplicarán por medio de cuatro ejes, dentro de los cuales, a su vez, existe una serie de medidas a las que se debe acoger cada Estado miembro, centrándonos en nuestro estudio en los ejes que gestionarán el Método LEADER. Estos cuatro ejes vienen plasmados además en el Plan de Desarrollo Nacional y en el Programa de Desarrollo Rural de Extremadura donde se especifican las medidas horizontales a financiar y que en el caso extremeño se concretaron en:

- Eje 1. Aumento de la competitividad del sector agrícola y forestal. Con medidas destinadas a fomentar el conocimiento y mejora del potencial humano, la reestructuración y desarrollo del potencial físico y fomento de la innovación y la mejora de la calidad de producción agrícola. Se financiarán ayudas para la gestión de los recursos hídricos, aumento del valor añadido de las producciones agrícolas y forestales, puesta en marcha de los servicios de asesoramiento a las explotaciones agrarias e instalación de jóvenes agricultores.

- Eje 2. Mejora del medio ambiente y del entorno rural. Engloba medidas destinadas a la utilización sostenible de tierras agrícolas y forestales. Se financiarán ayudas para la prevención de incendios forestales y la Red Natura 2000 en el medio forestal.

- Eje 3. Calidad de vida en las zonas rurales y diversificación de la economía rural. Con medidas de diversificación económica del medio rural y mejora de la calidad de vida del mismo, así como una medida relativa a la formación e información de 
agentes económicos y otra a la adquisición de capacidades y promoción, con el fin de elaborar y aplicar una estrategia de desarrollo rural.

- Eje 4. Método Leader. El Eje 4 es donde se aplicará lo que se conoce como enfoque o metodología Leader en cuanto a estrategia de desarrollo local por zonas, a través de partenariados entre los sectores públicos y privados donde se gestionarán además las medidas del Eje 3 y una submedida del Eje 1. Aumento de la competitividad del sector agrícola y forestal.

Seguirán los mismos planteamientos de funcionamiento que en etapas anteriores de LEADER y PRODER y se mantendrán como un método diferente y alternativo de intervención frente al tradicional de la Administración Pública, por estar basado en desarrollar un conjunto de intervenciones sobre un territorio concreto mediante la aplicación de una estrategia de desarrollo elaborada y ejecutada por el GAL con la participación de la población rural («bottom - up»).

De los 1.188.306,80 euros de contribución pública destinados a la región extremeña, el $66 \%$ pertenece al FEADER y el resto es de contribución nacional (AGE y Gobierno Autonómico). Por Ejes, destacar que el Eje 3 se financia con un $75 \%$ de inversiones públicas y el Eje 4 el $80 \%$, por ser región Objetivo de Convergencia. Un aspecto a destacar, es que en este período de actuación a los Grupos LEADER no se les exige la subvención de proyectos con ayuda financiera de entidades locales, ayuntamientos fundamentalmente en el caso extremeño, como sí sucedía en períodos de programación anteriores. Se puede observar en la Tabla 1 el Plan Financiero por ejes especificado en el PDR de Extremadura 2007-2013.

Tabla 1

PLAN FINANCIERO DEL FEADER (2007-2013) POR EJES

\begin{tabular}{|c|r|c|r|r|r|}
\cline { 4 - 6 } \multicolumn{2}{c}{} & \multicolumn{4}{c|}{ Contribución Nacional } \\
\hline EJE & $\begin{array}{l}\text { Contribución } \\
\text { Pública Total }\end{array}$ & FEADER & \multicolumn{1}{c|}{ Total } & \multicolumn{1}{c|}{ AGE } & $\begin{array}{c}\text { Administración } \\
\text { Autonómica }\end{array}$ \\
\hline Eje 2 & 577.686 .663 & 371.741 .304 & 205.945 .259 & 107.404 .626 & 98.540 .633 \\
\hline Eje 3 & 463.263 .016 & 291.855 .700 & 171.407 .316 & 91.038 .759 & 80.368 .557 \\
\hline Eje 4 & 114.503 .823 & 91.603 .058 & 22.900 .765 & 11.943 .215 & 10.957 .550 \\
\hline $\begin{array}{l}\text { Asistencia } \\
\text { Técnica }\end{array}$ & 2.079 .573 & 1.559 .680 & 519.893 & 271.135 & 248.758 \\
\hline Total & 1.188 .306 .680 & 779.839 .945 & 408.466 .635 & 214.670 .000 & 193.796 .635 \\
\hline
\end{tabular}

Fuente: Programa de Desarrollo Rural de Extremadura (2007-2013).

Dentro de este cuadro financiero regional, los Grupos de Acción Local gestionarán todas las medidas y submedidas de los Ejes 3 y 4 y una submedida del Eje 1, siendo las que se muestran en la tabla siguiente: 
Tabla 2

EJES DE FINANCIACIÓN DEL FEADER

\begin{tabular}{|c|c|c|}
\hline Eje 1 & Eje 3 & Eje 4 \\
\hline $\begin{array}{l}\text { Medida } 413 . \text { Aumento } \\
\text { de la Competitividad } \\
\text { del sector agrícola y } \\
\text { forestal }\end{array}$ & $\begin{array}{c}\text { Medida 413. Mejora de la calidad de vida y de } \\
\text { la economía en las zonas rurales }\end{array}$ & Método LEADER \\
\hline Submedidas & Submedidas & Submedidas \\
\hline \multirow{8}{*}{$\begin{array}{l}\text { 123. Aumento del } \\
\text { valor añadido de los } \\
\text { productos agrícolas y } \\
\text { forestales }\end{array}$} & $\begin{array}{l}\text { 311. Diversificación hacia actividades no } \\
\text { agrícolas }\end{array}$ & \multirow{4}{*}{$\begin{array}{l}\text { 421. Cooperación } \\
\text { Transnacional e } \\
\text { Internacional. }\end{array}$} \\
\hline & $\begin{array}{l}\text { 312. Ayudas a la creación y al desarrollo de } \\
\text { microempresas }\end{array}$ & \\
\hline & 313. Fomento de actividades turísticas & \\
\hline & $\begin{array}{l}\text { 321. Servicios básicos para la economía y la } \\
\text { población rural }\end{array}$ & \\
\hline & $\begin{array}{l}322 . \text { Renovación y desarrollo de poblaciones } \\
\text { rurales }\end{array}$ & \multirow{4}{*}{$\begin{array}{l}\text { 431. Funcionamiento } \\
\text { del Grupo de Acción } \\
\text { Local, adquisición } \\
\text { de capacidades y } \\
\text { promoción territorial }\end{array}$} \\
\hline & $\begin{array}{l}\text { 323. Conservación y mejora del patrimonio } \\
\text { rural }\end{array}$ & \\
\hline & $\begin{array}{l}\text { 331. Formación e información de los agentes } \\
\text { económicos que desarrollen sus actividades en } \\
\text { los ámbitos cubiertos por el Eje } 3\end{array}$ & \\
\hline & $\begin{array}{l}\text { 341. Adquisición de capacidades y promoción } \\
\text { con vistas a la elaboración y aplicación de una } \\
\text { estrategia de desarrollo local }\end{array}$ & \\
\hline
\end{tabular}

Fuente: Programa de Desarrollo Rural de Extremadura (2007-2013).

Una novedad introducida en la gestión de las ayudas del FEADER en Extremadura ha sido la incorporación de la Submedida 123: «Aumento del valor añadido de los productos agrícolas y forestales» del Eje 1 al Método Leader. Hasta el mes de abril de 2012, toda actividad agroindustrial, independientemente del importe de la inversión, estaba vedada. Sin embargo, a partir de dicho mes, se traslada a LEADER la posibilidad de incorporar proyectos de inversión inferiores a 200.000 euros, destinados a la creación, ampliación y/o mejora de micro, pequeñas o medianas empresas agroalimentarias en zonas en las que se considere que la viabilidad de la economía local está ligada al desarrollo de la industria agroalimentaria que transforma y comercializa la producción local. Estas actuaciones son las que se encuadran en las ayudas de la Submedida 123.

A nivel territorial, actualmente en Extremadura existen 24 Grupos de Acción Local que gestionan estas ayudas al desarrollo rural bajo el enfoque o «Metodología Leader». Estos Grupos ocupan una superficie de $37.369 \mathrm{Km}^{2}$ (un 89,7 \% del total regional), 379 municipios (el $98,9 \%$ del total) y 761.157 habitantes (el 70,9\% de Extremadura). Por ello, podemos afir- 
mar que en todo el territorio extremeño, en la actualidad, se está gestionando un programa de desarrollo rural LEADER excepto los cuatro municipios considerados como urbanos y que tienen más de 40.000 habitantes: Cáceres, Badajoz, Mérida y Plasencia. De ahí, la importancia de estudios como este trabajo por el posible impacto territorial y demográfico que tiene el método LEADER en territorios como el extremeño.

\section{LA IMPLANTACIÓN DE LEADER EN EL TERRITORIO EXTREMEÑO}

En este epígrafe nos centraremos en estudiar la evolución y la implantación del Método LEADER en Extremadura desde 1995 hasta la actualidad, al no incluirse los datos de LEADER I por ser una experiencia pionera que tuvo escasa repercusión territorial y económica, sólo se implantó en 4 Grupos de Acción Local con un presupuesto total de 17 millones de euros (Nieto y Gurría, 2008).

La denominación de las Medidas financiables en LEADER han ido cambiando según las normativas de los distintos periodos de programación, desde LEADER II (1995-1999) hasta el actual FEADER (2007-2013), a la vez que también fueron diferentes a las establecidas en las etapas del Programa PRODER (1995-2006), por lo que, para un mejor análisis de las mismas y un estudio evolutivo, es conveniente llevar a cabo su homogeneización. Teniendo en cuenta la normalización y homogeneización entre las Medidas de LEADER y PRODER llevadas a cabo por Nieto y Gurría (2008), y uniendo las pertenecientes al FEADER (20072013), en esta investigación hemos completado esta metodología agrupando todos los proyectos subvencionables de las distintas etapas del Método LEADER en siete acciones, como podemos observar en la tabla 3.

En Extremadura, desde 1995 con la etapa de LEADER II-PRODER I, se han invertido más de 425 millones de euros, de los cuales el $55 \%$ eran fondos públicos (40\% provenientes de la Unión Europea y el $15 \%$ restante de las administraciones nacionales) y el $44 \%$ tendría origen en el sector privado (Fig. 1). En las distintas etapas de LEADER y PRODER se ha financiado a través de distintos Fondos Estructurales de la Unión Europea (FEDER, FEOGA-O, FSE y en la actualidad FEADER) y en las aportaciones de las administraciones nacionales han participado la Administración General del Estado, el Gobierno Regional y en los períodos 1994-2006 la Administración Local en LEADER II, PRODER I y LEADER + ${ }^{2}$.

Un aspecto primordial a destacar, es la muy importante aportación de la inversión privada, que supone casi la mitad de las inversiones totales (44\% de 425 millones de inversiones en proyectos). Estos datos nos permiten interpretar, de entrada, la importante capacidad de movilización que se ha tenido desde los GAL respecto al sector privado, en los respectivos territorios. La percepción que tenía la población sobre el mundo rural está cambiando, por empezar a ser considerados como lugares con importantes oportunidades de inversión y donde el sector privado es el gran protagonista de Iniciativas como el Método LEADER, en la medida en la que, moviliza y da forma a tales oportunidades a través de sus inversiones. El tejido empresarial es un sector clave para el desarrollo de los territorios rurales y cada vez está más comprometido con él al implicarse en la financiación de nuevos proyectos.

2 En LEADERII-PRODER I (1994-1999) la aportación de la administración local fue del 7,45 del total de inversiones y en el período siguiente (2000-2006) sólo se ejecutó en LEADER + con el 5,95 \%. 
Tabla 3

HOMOGENEIZACIÓN DE MEDIDAS LEADER, PRODER Y FEADER

\begin{tabular}{|c|c|c|c|c|c|}
\hline & LEADER II & LEADER + & PRODER I & PRODER II & FEADER 2007/2013 \\
\hline \multirow{3}{*}{$\begin{array}{l}\text { Acción 1. Gastos } \\
\text { de funciona- } \\
\text { miento }\end{array}$} & \multirow[t]{3}{*}{ B1. Apoyo Técnico } & 102.Gastos de Gestión & \multirow{3}{*}{$\begin{array}{l}\text { 6. Servicios a } \\
\text { Empresas }\end{array}$} & \multirow{3}{*}{$\begin{array}{l}\text { 1. Gastos de Funcio- } \\
\text { namiento }\end{array}$} & $\begin{array}{l}\text { 341. Adquisición de capa- } \\
\text { cidades y promoción con } \\
\text { vistas a la elaboración y } \\
\text { aplicación de una estrate- } \\
\text { gia de desarrollo local }\end{array}$ \\
\hline & & $\begin{array}{l}\text { 103. Servicios a la } \\
\text { Población. }\end{array}$ & & & $\begin{array}{l}\text { 431. Funcionamiento del } \\
\text { Grupo de Acción Local, }\end{array}$ \\
\hline & & 109. Otras Inversiones & & & $\begin{array}{l}\text { adquisición de capacidades } \\
\text { y promoción territorial }\end{array}$ \\
\hline $\begin{array}{l}\text { Acción 2. Forma- } \\
\text { ción y empleo }\end{array}$ & $\begin{array}{l}\text { B2. Formación y } \\
\text { Ayuda al Empleo }\end{array}$ & $\begin{array}{l}\text { 110.Formación y } \\
\text { Empleo }\end{array}$ & & 2.Formación & $\begin{array}{l}\text { 331. Formación e informa- } \\
\text { ción de los agentes econó- } \\
\text { micos que desarrollen sus } \\
\text { actividades en los ámbitos } \\
\text { cubiertos en el Eje } 3\end{array}$ \\
\hline \multirow[b]{2}{*}{$\begin{array}{l}\text { Acción } 3 . \mathrm{Tu}- \\
\text { rismo }\end{array}$} & \multirow[b]{2}{*}{ B3. Turismo Rural } & \multirow[b]{2}{*}{ 108. Turismo Rural } & 3.Agroturismo & & \multirow[b]{2}{*}{$\begin{array}{l}\text { 313. Fomento de activida- } \\
\text { des turísticas }\end{array}$} \\
\hline & & & $\begin{array}{l}\text { 4. Turismo } \\
\text { Local }\end{array}$ & 3. Turismo Rural & \\
\hline \multirow{2}{*}{$\begin{array}{c}\text { Acción } 4 . \\
\text { PYMES, Arte- } \\
\text { sanía y Servicios }\end{array}$} & \multirow[b]{2}{*}{$\begin{array}{l}\text { B4.PYMES, Arte- } \\
\text { sanía y Servicios }\end{array}$} & \multirow[b]{2}{*}{$\begin{array}{l}\text { 106. PYMES y Ser- } \\
\text { vicios }\end{array}$} & \multirow{2}{*}{$\begin{array}{l}\text { 5. PYMES, } \\
\text { Artesanía y } \\
\text { Servicios }\end{array}$} & \multirow[b]{2}{*}{$\begin{array}{l}\text { 4.PYMES, Artesanía y } \\
\text { Servicios }\end{array}$} & $\begin{array}{l}\text { 311. Diversificación hacia } \\
\text { actividades no agrícolas }\end{array}$ \\
\hline & & & & & $\begin{array}{c}\text { 312. Ayudas a la creación } \\
\text { de y al desarrollo de } \\
\text { microempresas }\end{array}$ \\
\hline $\begin{array}{c}\text { Acción } 5 \text {. Valori- } \\
\text { zación de la pro- } \\
\text { ducción agraria } \\
\text { y forestal }\end{array}$ & $\begin{array}{c}\text { B5. Valorización y } \\
\text { Comercialización } \\
\text { de la Producción } \\
\text { Agraria, Silvícola y } \\
\text { Forestal }\end{array}$ & $\begin{array}{l}\text { 105.Valorización de } \\
\text { Productos Locales } \\
\text { Agrarios }\end{array}$ & $\begin{array}{l}\text { 7.Revalori- } \\
\text { zación del } \\
\text { potencial } \\
\text { productivo } \\
\text { agrario y } \\
\text { forestal }\end{array}$ & $\begin{array}{l}\text { 5. Revalorización del } \\
\text { potencial productivo } \\
\text { agrario y forestal }\end{array}$ & $\begin{array}{l}\text { 123. Aumento del valor } \\
\text { añadido de los productos } \\
\text { agrícolas y forestales }\end{array}$ \\
\hline \multirow{3}{*}{$\begin{array}{l}\text { Acción 6. Con- } \\
\text { servación y mejo- } \\
\text { ra del Patrimo- } \\
\text { nio y el Medio } \\
\text { Ambiente }\end{array}$} & \multirow{3}{*}{$\begin{array}{l}\text { B6.Conservación y } \\
\text { Mejora del Medio } \\
\text { Ambiente y Entorno }\end{array}$} & $\begin{array}{l}\text { 104. Patrimonio } \\
\text { Natural }\end{array}$ & $\begin{array}{l}\text { 1. Valori- } \\
\text { zación del } \\
\text { Patrimonio } \\
\text { Rural }\end{array}$ & \multirow{3}{*}{$\begin{array}{l}\text { 6. Valorización del } \\
\text { Patrimonio Rural }\end{array}$} & $\begin{array}{c}\text { 321. Servicios básicos para } \\
\text { la economía y la población } \\
\text { rural }\end{array}$ \\
\hline & & \multirow{2}{*}{$\begin{array}{l}\text { 107.Valorización del } \\
\text { Patrimonio Cultural y } \\
\text { Arquitectónico }\end{array}$} & \multirow{2}{*}{$\begin{array}{l}\text { 2. Valori- } \\
\text { zación del } \\
\text { Patrimonio } \\
\text { Local }\end{array}$} & & $\begin{array}{l}\text { 322. Renovación y desarro- } \\
\text { llo de poblaciones rurales. }\end{array}$ \\
\hline & & & & & $\begin{array}{l}\text { 323. Conservación y mejo- } \\
\text { ra del patrimonio rural }\end{array}$ \\
\hline \multirow{2}{*}{$\begin{array}{l}\text { Acción } 7 . \text { Coope- } \\
\text { ración }\end{array}$} & \multirow{2}{*}{$\begin{array}{l}\text { C1. Cooperación } \\
\text { Transnacional }\end{array}$} & $\begin{array}{l}\text { 201.Cooperación } \\
\text { Interterritorial }\end{array}$ & & & \multirow{2}{*}{$\begin{array}{l}\text { 421. Cooperación trans- } \\
\text { nacional } \\
\text { e interregional }\end{array}$} \\
\hline & & $\begin{array}{c}\text { 202.Cooperación } \\
\text { Transnacional }\end{array}$ & & & \\
\hline
\end{tabular}

Fuente: elaboración propia a partir de la metodología de Nieto y Gurría (2008). 
No solamente destacar la gestión de los GAL en el método LEADER para obtener una alta participación privada sino considerar también el protagonismo de factores de entorno, como son las propias dinámicas de cambio y transformación social y/o económica, presentes en muchos territorios rurales.

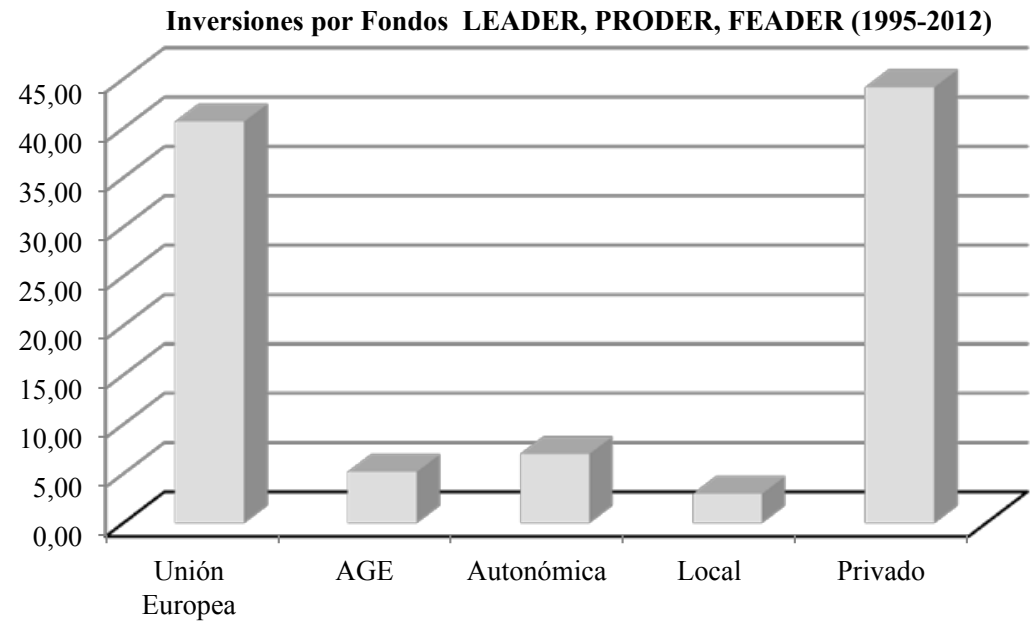

Fuente: elaboración propia a partir de datos del Gobierno de Extremadura y Redex.

Destacamos que en las sucesivas etapas del método LEADER las cifras previstas al inicio de los períodos de programación fueron inferiores a las finalmente comprometidas y ejecutadas. En todos los períodos ha habido un incremento debido a la movilización de la inversión privada y al esfuerzo de la participación de todas las administraciones nacionales. Sus inversiones aumentaron de manera considerable pasando de los 127 millones de euros de la $1^{\circ}$ etapa (1994-1999) a los 195 millones en la segunda (2000-2006) y la previsión de concluir ésta última etapa con 173.809.646 millones (2007-2013), aunque esta última cantidad todavía se podría incrementar como en etapas anteriores si desde la gestión de los GAL se puede conseguir aumentar la participación privada o de las administraciones nacionales como ha ocurrido en los dos períodos anteriores. Aunque querríamos añadir como un efecto menos positivo en la gestión de LEADER que en este último período, en FEADER, ha desaparecido la obligatoriedad de participar en las inversiones las administraciones locales debido a los problemas de financiación que tienen los ayuntamientos en el territorio español y que estaban dificultando en las anteriores etapas que los presupuestos finales comprometidos se pudieran ejecutar por sus retrasos y debilidades económicas. En este nuevo período pueden participar con financiación pero sus aportaciones serán consideradas como aportación privada.

Todas estas inversiones han ido destinadas principalmente a las tres medidas productivas, A 3 (Turismo), A 4 (PYMES, artesanía y comercio) y A 5 (Valorización de la producción agraria) (Fig. 2), a través de 8.490 proyectos, suponiendo el $68 \%$ del total. 


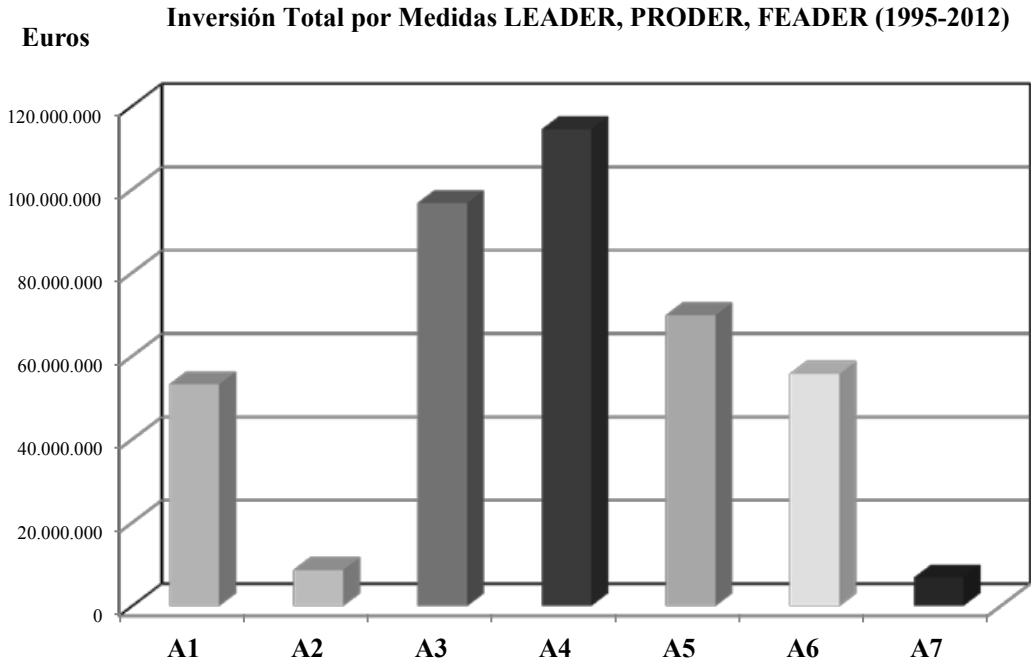

Fuente: elaboración propia a partir de datos del Gobierno de Extremadura y Redex.

A lo largo de los años se ha podido observar cómo los Grupos de Acción Local han ido apostando por estrategias dependientes de las necesidades de sus territorios. De este modo, en la primera etapa (LEADER II-PRODER I) optaron por la explotación de sus ricos recursos, tanto naturales como histórico-artísticos, teniendo en cuenta que el Turismo Rural podía ser una buena actividad alternativa que ayudara a combatir la crisis del sector agrario $(25,57$ $\%$ del total de inversiones, mucho más diferenciadas con LEADER II con un $22 \%$ y PRODER I con un $27 \%)^{3}$. Posteriormente, aprovecharon las experiencias adquiridas, para la dinamización de su tejido empresarial, aumentando tanto en la segunda etapa como en el período actual las inversiones en las acciones 4 y 5 (Artesanía, Turismo y Pymes y Revalorización de la Producción Agraria) (Fig. 3).

Analizando también con más detalle la tipología de proyectos e inversiones hemos añadido la tabla 4 donde se han introducido una serie de indicadores de las tres etapas. De las dos primeras, con los períodos de programación ya finalizados y en la tercera con datos de ejecución a 30 de septiembre del 2012. Sólo indicar que todavía con estos datos del FEADER se ha comprometido sólo un 47,11 \% del total previsto, un nivel de ejecución bastante bajo por las dificultades que ha tenido este Programa en iniciar sus convocatorias de inversión de proyectos, debido a su complejidad de ejecución en comparación con etapas anteriores, lo que ha exigido una readaptación de los sistemas necesarios para la gestión y control de las ayudas, por la novedad de esta etapa de incluirlos en este período dentro de los Programas Nacionales de Desarrollo Rural.

3 Al no financiarse en PRODER I la cooperación transnacional ni la formación y el empleo ni exigirse un reparto equilibrado entre las tres medidas productivas, sus inversiones se centraron principalmente en la potenciación del sector turístico como una actividad primordial en el desarrollo de sus territorios. 
Figura 3

DISTRIBUCIÓN DE LA INVERSIÓN EN LAS DISTINTAS ETAPAS DEL MÉTODO LEADER (1995-2012)

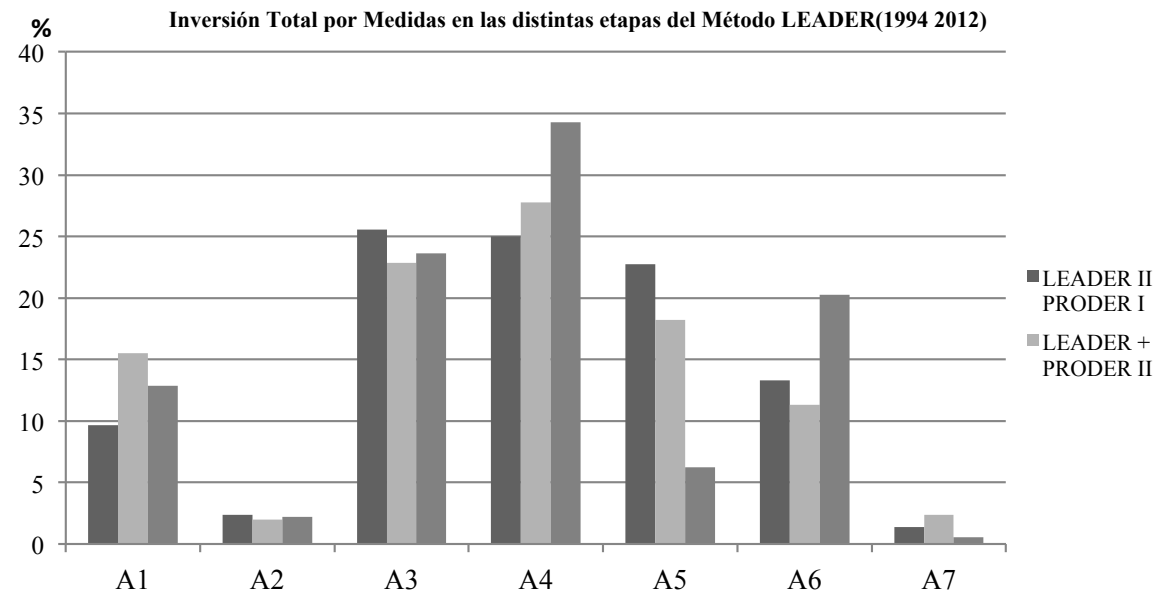

Fuente: elaboración propia a partir de datos del Gobierno de Extremadura y Redex.

Tabla 4

Indicadores Método LEADER (1995-2012)

\begin{tabular}{|l|c|c|c|}
\hline \multicolumn{1}{|c|}{ INDICADORES } & $\mathbf{1 9 9 5 - 1 9 9 9}$ & $\mathbf{2 0 0 0 - 2 0 0 6}$ & $\mathbf{2 0 0 7 - 2 0 1 3}$ \\
\cline { 2 - 4 } & $\begin{array}{c}\text { LEADER II - } \\
\text { PRODER I }\end{array}$ & $\begin{array}{c}\text { LEADER + - } \\
\text { PRODER II }\end{array}$ & FEADER \\
\hline Grupos de Acción Local & 22 & 24 & 24 \\
\hline Municipios & 302 & 374 & 379 \\
\hline Población & $\begin{array}{c}563.855 \\
(52,9 \%)\end{array}$ & $\begin{array}{c}759.055 \\
(69.6 \%)\end{array}$ & $\begin{array}{c}761.157 \\
(70,9 \%)\end{array}$ \\
\hline Superficie (Km) & $\begin{array}{c}31.100 \\
(74 \%)\end{array}$ & $\begin{array}{c}37.228 \\
(89,32 \%)\end{array}$ & $\begin{array}{c}37.369,78 \\
(89,7 \%)\end{array}$ \\
\hline Inversiones previstas a inicio de programa & 111.591 .161 & 156.997 .910 & 173.809 .646 \\
\hline Inversiones ejecutadas y comprometidas & 128.608 .329 & 195.027 .487 & 85.260 .222 \\
\hline I. Privadas previstas a inicio de programa (\%) & 46,28 & 45,08 & 30,67 \\
\hline I. Privadas ejecutadas y comprometidas (\%) & 46,30 & 54,50 & 47,11 \\
\hline Proyectos & 3.372 & 3.638 & 1480 \\
\hline Media de inversiones por proyecto & 37.891 & 53.608 & 57.608 \\
\hline
\end{tabular}

Fuente: elaboración propia a partir de datos del Gobierno de Extremadura y Redex. 
Se pueden obtener una serie de resultados: se han incrementado las inversiones en las tres etapas, la participación privada y el número de proyectos, aunque éstos últimos no tan significativamente como las inversiones. Sobre todo, destacar el incremento de la cuantía económica media de las inversiones de cada proyecto (un 35 \% desde 1995). En los primeros años eran de menor envergadura, puesto que el empresario privado todavía dudaba de invertir en nuevas estrategias de actividades económicas en su territorio y la consolidación de este método, la labor divulgadora de los equipos técnicos de los Grupos y el cambio de mentalidad en estas zonas está propiciando este aumento en las inversiones privadas totales y en proyectos de mayor tamaño y consolidación en el territorio (con una inversión media de más de 57.000 euros por proyecto).

La mayoría de estos proyectos están orientados a la diversificación hacia actividades no agrícolas, con el fin de fortalecer su estructura productiva, la mejora de su rendimiento económico y el fomento de una cultura emprendedora e iniciativa empresarial entre los agricultores y sus familias; a la creación y desarrollo de microempresas, con el objeto de contribuir a la creación, ampliación y modernización de las mismas, para poder contribuir así en el mayor rendimiento de la economía local y teniendo en cuenta las necesidades de ésta; y al fomento de actividades turísticas, establecimientos hoteleros, y creación de un «producto turístico» ${ }^{4}$, fortaleciendo y complementando la infraestructura ya existente del sector turístico local a través de actividades de carácter no productivo, como centros de información, centros de interpretación y pequeños museos, siempre y cuando estén relacionados con la etnografía, la cultura, el medio ambiente, la agricultura y la pesca, así como la señalización de los lugares turísticos que potencien el turismo rural, éstos desarrollados, en muchos casos, gracias a inversiones llevadas a cabo anteriormente con LEADER y PRODER.

\section{LOS EFECTOS DEL MÉTODO LEADER EN LOS GRUPOS DE ACCIÓN LOCAL DE EXTREMA- DURA}

La distribución de las inversiones del método LEADER en los diferentes Grupos (Tabla 5), tanto en número de proyectos como en cantidades de dinero, se puede identificar con las variadas realidades socioeconómicas que presenta la región. De este modo, las ayudas han ido destinadas a los sectores más consolidados en cada uno de los territorios y así sus Grupos de Acción Local, aún tratando de luchar por la diversificación hacia actividades no agrarias, han centrado sus esfuerzos en aprovechar los sectores ya generados anteriormente y explotarlos en beneficio de la población local.

Las mayores inversiones han tenido lugar en los ejes ya tradicionales del desarrollo extremeño, por lo que el impacto territorial no ha sido tan notorio. Así, por un lado, nos encontramos áreas de mayor dinamismo económico y demográfico (Fig. 4 con indicadores demográficos y económicos), localizadas en los territorios en los que la agricultura ha sufrido procesos de modernización, coincidiendo con las zonas de regadío y cuencas de secano sedimentarias, en las que se ha desarrollado también una potente agroindustria

4 En FEADER se hace hincapié a través de la Medida 313, la necesidad de crear un producto turístico de cada territorio con ofertas complementarias de alojamientos, restauración, artesanía, patrimonio y ocio y dentro de una marca común que pueda ser exportada como signo identificativo de cada comarca de actuación. 
(Vegas del Guadiana y Valle del Alagón con el regadío y Barros Oeste con el secano) o con un sector servicios e industrial importante, por la proximidad a las principales ciudades (Tajo-Salor-Almonte). Destacar el caso de La Serena y Campiña Sur, que presentando un atraso socioeconómico importante y una dinámica demográfica regresiva, consecuencia de la escasa explotación de sus recursos por diversas dificultades físicas del territorio, obtienen en la gestión del método LEADER, unas de las mayores inversiones (Fig. 5). Todos estos Grupos han superado las inversiones de 20 millones de euros en sus territorios y coinciden con los ejes de Coria-Plasencia- al norte de Cáceres (regadíos del Árrago-Alagón-Ambroz) y el eje de las Vegas del Guadiana-Tierra de Barros, con Badajoz-Montijo-Mérida-Don BenitoVillanueva, al norte de Badajoz en las Vegas, y Almendralejo-Villafranca-Zafra en centro de la provincia en Tierra de Barros. Coincide con la concentración de población, empleo, equipamientos y servicios, como podemos observar en los mapas del Índice de Actividad Económica, PIB y Tamaño de la Población (Fig. 4). Se puede afirmar que estas políticas de Desarrollo Rural padecen una elevada discriminación positiva hacia los espacios rurales más dinámicos, concentrándose las actuaciones en los núcleos con mayor dinamismo económico, donde se encuentran los empresarios más solventes y emprendedores (Nieto y Gurría, 2008; Cejudo y Navarro, 2009). En estos Grupos además se ha optado por invertir en las medidas de la Acción 4 (Pymes, Artesanía y Servicios) seguida de la Acción 5 (revalorización de la producción agraria). Destacamos los más de 11 millones de Tajo-Salor, 9 de Lácara y 7 de Barros Oeste localizados en las zonas con mayor productividad agraria y/o cercanas a los principales núcleos de población de Extremadura: Badajoz, Cáceres y Mérida.

Por otro lado, nos encontramos con zonas en declive demográfico y económico, localizadas en la penillanura y en la montaña, territorios en los que por sus limitaciones físicas no se ha podido llevar a cabo la modernización de sus estructuras agrarias y que se caracterizan por la improductividad de sus explotaciones minifundistas en la montaña y latifundistas en la penillanura y, por su escasa población, además de envejecida (Fig. 4), en las que se ha optado por la estrategia del Turismo Rural, debido a la inexistencia de iniciativa privada y, por otra parte, a la disponibilidad de ricos recursos naturales y culturales. Se trata de los Grupos de Acción Local de Hurdes, Monfragüe, Trasierra-Cáparra, Ambroz, La Vera y en menor medida, Jérez- S.SO y Villuercas-Ibores con las menores inversiones (Fig. 5). Parece que aun habiendo optado por explotar de manera significativa un sector en alza como es el Turismo Rural, siguen viendo cómo su población sigue en regresión y con un alto envejecimiento de la misma.

Atendiendo al número de proyectos no estableceríamos el mismo orden, sino que nos aparecerían que donde se ha localizado el mayor número, es en Grupos de montaña como Sierra de Gata, Valle del Jerte y Miajadas - Trujillo con unas inversiones entre 17 y 20 millones que, aunque no son de los de mayores inversiones, sí están entre los más efectivos en conseguir los mismos. En el siguiente ranking estarían Grupos como Tajo-Salor o Campiña Sur, que sí son de los que han tenido mayor volumen de inversiones (más de 20 millones), todos ellos con más de 570 proyectos hasta los 638 máximos del Valle del Jerte. Estableceríamos que la media de proyectos por Grupo es 353 y en los casos anteriores casi doblan la media en oposición a los que menores proyectos han tenido, que casi coinciden con la anterior lista de las menores inversiones (Monfragüe, Trasierra-Cáparra, Jérez-S.SO con menos de 200 proyectos). 
Comprobando también otro factor, como es la participación privada en el volumen de inversiones, destacamos los Grupos localizados en las Vegas del Guadiana, Barros y la Siberia con más del $55 \%$ de participación, coincidiendo con el análisis que hicimos en párrafos anteriores con los Grupos de mayores inversiones.

Estos indicadores (mayor volumen de inversión, de proyectos y participación privada) nos muestran una primera aproximación al funcionamiento y la distribución del método LEADER, pero no queremos ceñirnos solamente a estos datos sino también relacionarlo con el territorio sobre el que se asienta cada uno de ellos. Por ello, añadimos unos indicadores donde relacionamos tanto las inversiones como los proyectos con el territorio y la población. Si lo relacionamos con la población comprobaremos que Grupos que han tenido menor volumen de inversiones totales como los localizados en la montaña como Hurdes, Valle del Jerte, Valle del Ámbroz, Sierra de Gata, La Vera, Trasierra-Cáparra o VilluercasIbores son de los que más recursos de inversión han generado, superando en todos estos casos las media de 22,72 proyectos por $100 \mathrm{Km}^{2}$ y 11,14 por mil habitantes, y 1,09 millones de euros de inversiones por $100 \mathrm{Km}^{2}$ y 535. 611 Euros por mil habitantes (Tabla 4). Es decir, el territorio y la estructura de la población, en muchos grupos muy envejecida, condiciona el volumen total de inversiones o proyectos que en un primer análisis nos indica que se ha conseguido movilizar menos recursos, pero es que estamos analizando Grupos con municipios con poca extensión y población (la dicotomía de municipios con mayor extensión territorial y núcleos más poblados en las zonas de penillanura y regadío de la provincia de Badajoz en contraste de municipios poco extensos y poblados de las zonas de montaña de la provincia de Cáceres). Se han financiado, en estas zonas, un volumen de proyectos considerable, pero de menor cuantía económica al estar ligados a la actividad turística y no a la implantación o mejora de PYMES, Agroindustria o Servicios que suelen ser proyectos de mayor envergadura. Añadir que este tipo de proyectos no generan tanto volumen de empleo ni beneficios económicos en los municipios donde se asientan para frenar esas pérdidas y envejecimiento de su población.

En el último análisis hemos localizado el mayor volumen de inversiones a nivel municipal, donde se puede observar que se encuentra en los núcleos con mayor actividad económica, que además se corresponden con las diferentes cabeceras comarcales y centros de actividades agroindustriales, que gozan de una posición central en el sistema de comunicaciones y de diferentes equipamientos y servicios por la descentralización administrativa de la España de las Autonomías, repartidos por toda la región extremeña (Fig. 5). Además, prácticamente en todos los casos, es donde se ha localizado el CEDER y han estado más accesibles para la labor de consulta y dinamización de los técnicos de los GAL. Son los casos de Almendralejo, Don Benito, Cedillo, Villanueva de la Serena, Zafra, Jerez de los Caballeros, Navalmoral de la Mata, Miajadas, Villafranca de los Barros, Coria, Trujillo, Montijo y Castuera. Estos municipios son los que están actuando como cabeceras comarcales en el territorio extremeño, lo que supone que el resto de municipios rurales puedan obtener los suficientes servicios y equipamientos para su bienestar, desde sanitarios a educativos, administrativos, judiciales, etc, así como gozar de las instalaciones y labor de los Grupos de Acción Local. En la mayor parte de estos Grupos es donde se han localizado los proyectos con mayor volumen de inversión, normalmente relacionados con las Medidas 4 o 5, PYMES y Revalorización de la Producción Agraria. 


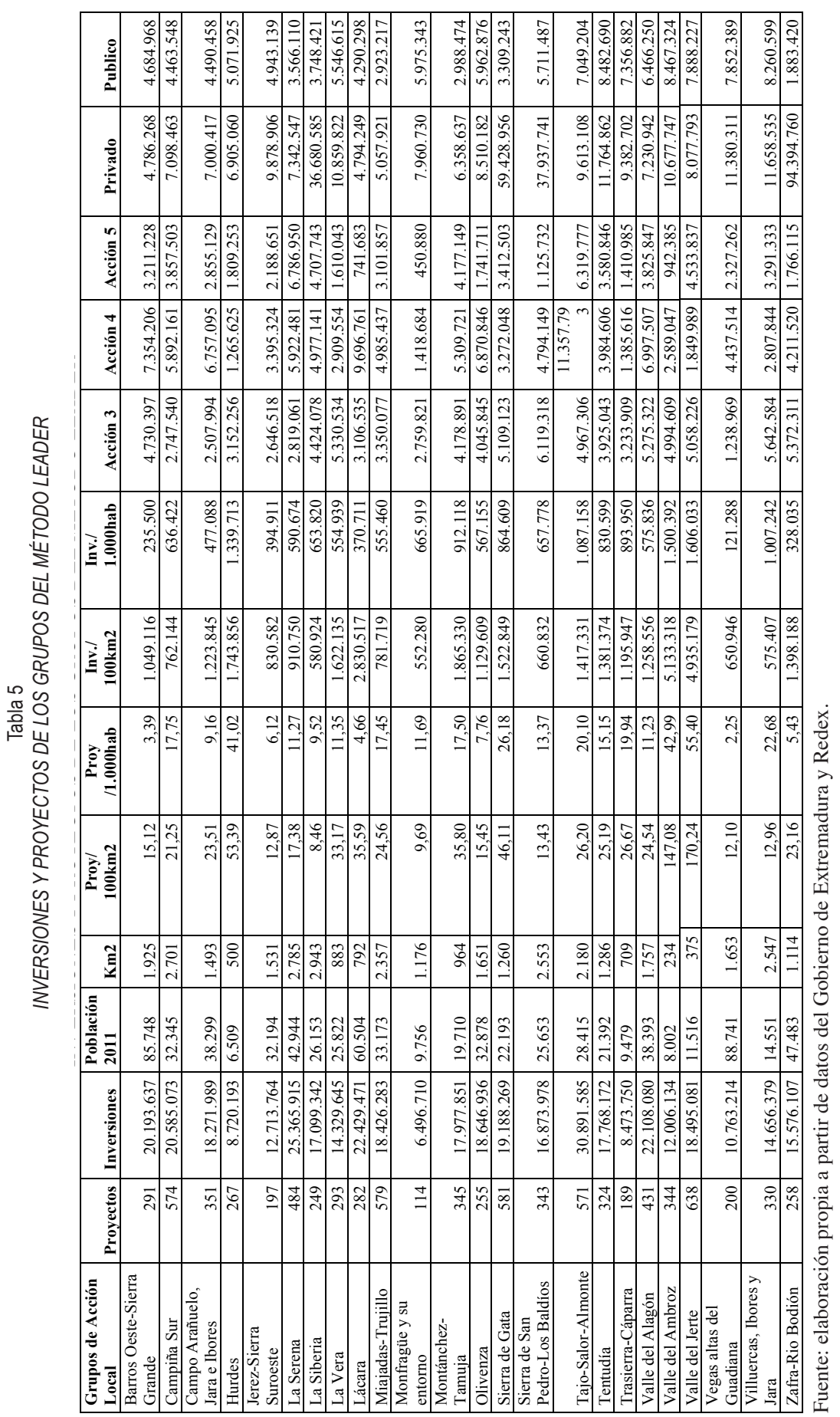




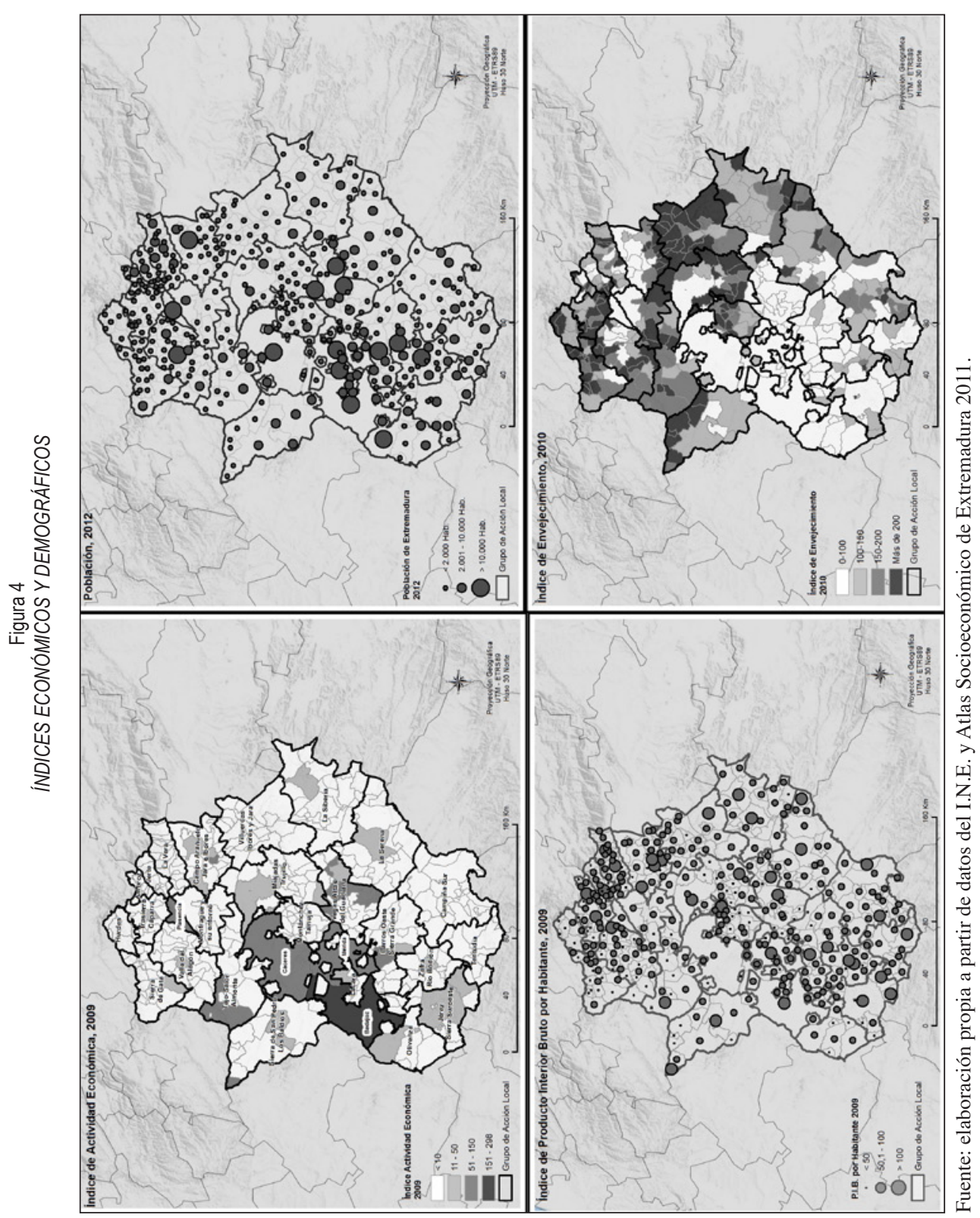




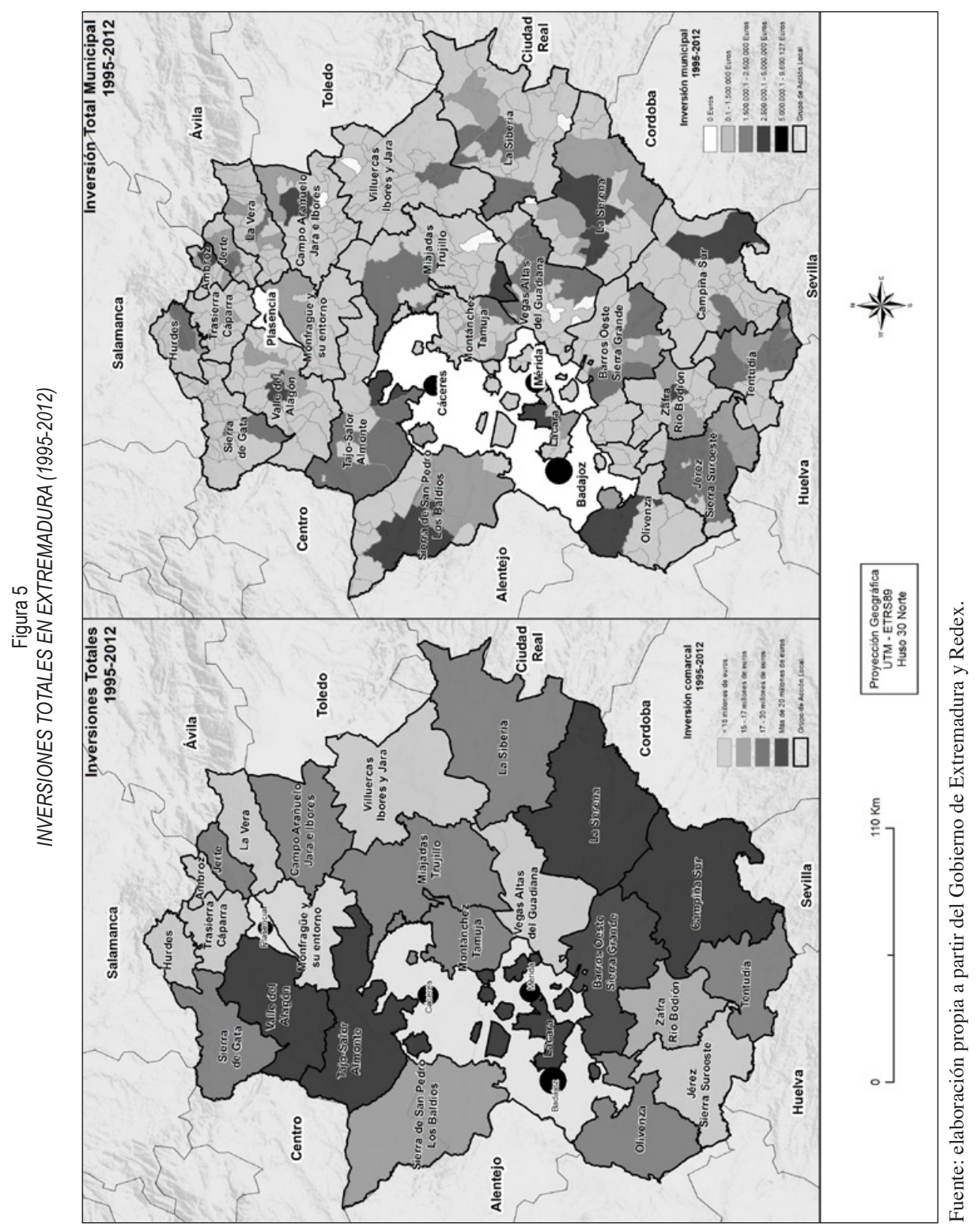




\section{CONCLUSIONES}

En este estudio nos hemos planteado analizar las acciones de LEADER y PRODER en Extremadura para comprobar si han contribuido a promover el desarrollo socioeconómico de los espacios rurales y si se han aproximado a los niveles de renta de las zonas urbanas. La evaluación de estas políticas, además, se nos plantea como una tarea fundamental hacía la sociedad porque estamos hablando de gestión de fondos públicos (ayudas de los Fondos Estructurales de la UE y de las Administraciones Nacionales) y tenemos que demostrar su valía ante la sociedad.

Hemos estudiado una serie de indicadores de contexto como las variables territoriales de cada Grupo (problemas demográficos como el envejecimiento y la concentración de la población, el índice de actividad económica) y las acciones realizadas por estas políticas de desarrollo (número de proyectos, inversiones, empleo, participación privada). También hemos incluido un análisis de la relación existente entre el presupuesto, la situación demográfica, la localización territorial y la actividad económica de los distintos Grupos. Estas políticas de desarrollo rural han producido efectos y resultados desiguales dependiendo del territorio y de las condiciones socioeconómicas de partida de cada uno de ellos. Se ha planteado una visión a escala municipal para destacar aspectos de desigualdades económicas o demográficas y a escala comarcal para ofrecer una visión de conjunto y comparativa entre las actuaciones de los diferentes GAL dentro del territorio extremeño. En general, desde los años 80, la población se ha ido estabilizando en sus lugares de origen, pero en las dos últimas décadas ha sido aún más notorio, debido sobre todo, a la mejora en la calidad de vida y condiciones socioeconómicas de las zonas rurales, de lo que son partícipes las ayudas al Desarrollo Rural, y a la exigencia, cada vez mayor, de empleo cualificado en las áreas urbanas, sin olvidar los inconvenientes presentados por la actual crisis económica. Así, los núcleos localizados en las áreas de regadío, los urbanos y algunos del norte de Cáceres, en el Valle del Jerte y La Vera, presentan un crecimiento natural positivo en las dos últimas décadas, así como en el sur de Badajoz. Sin embargo, las zonas más rurales, correspondientes con los municipios con menos de 2.000 habitantes, presentan un crecimiento natural negativo, en las zonas de montaña (Hurdes, Gata, Villuercas) y penillanura (Montánchez-Tamuja, Trujillo-Miajadas) y en algunos núcleos de secano y dehesas del sur de Badajoz.

En algunos territorios la consecución de los objetivos planteados (frenar la emigración, el envejecimiento, incrementar las actividades económicas...) no ha tenido los resultados esperados, debido, sobre a todo, a la escasez de recursos económicos, el efecto a veces negativo de otras políticas mejor financiadas (subsidio agrario, ayudas de la PAC,...) y las condiciones excesivamente negativas de su situación de partida (unas zonas muy envejecidas, aisladas y con un tejido industrial y económico casi inexistente) por lo que han resultado estas inversiones todavía escasas. Aunque, lo anterior no cuestiona que LEADER ha contribuido a generar una nueva forma de plantear estrategias de desarrollo con la participación de la población local en la toma de las decisiones, de mejora de la conciencia autóctona sobre las posibilidades de su territorio con inversiones en PYMES, agroindustria, artesanía, turismo o patrimonio, la creación de nuevas oportunidades en zonas que se sentían abandonadas por políticas de desarrollo autonómicas o nacionales. 
Es la única Iniciativa, junto a INTERREG, que se ha mantenido en todos los períodos de programación e incluso en este último (2007-2013) con la creación del FEADER se le otorga una nueva naturaleza al incluirla como un eje de intervención propio de dicho Fondo (Reglamento CE 1698/2005). Es una pequeña muestra de su éxito, si no la UE no seguiría financiándola y, de la insuficiencia de la PAC como único instrumento para el desarrollo rural. Nos hemos planteado, como recomienda la Comisión Europea, que los efectos de LEADER al evaluarlos no deben centrarse sólo en los resultados económicos (creación de empresas, generación de empleo, mejora de infraestructuras,...) sino en su proceso de contribución a experimentar la innovación, la transferencia de resultados y nuevos modelos de desarrollo en estos territorios tradicionalmente menos innovadores y con menos recursos económicos. Por ejemplo, tener en cuenta otras dimensiones como el grado de ejecución de sus presupuestos (se han incrementado en todos los períodos respecto a sus previsiones iniciales), la participación privada que han conseguido movilizar (con un $42 \%$ de las inversiones), una tendencia hacia el reparto equitativo entre todas las medidas de actuación (PYMES, Artesanía, Turismo, Revalorización de la Producción Agraria y Patrimonio) y la continuidad en el aspecto social de los GAL: por contribuir a la conciencia de comarca, a la participación de la población en las dinámicas de desarrollo rural y a la preocupación por la sostenibilidad ambiental. Además, destacamos el mantenimiento de los GAL en prácticamente todo su territorio rural desde el año 2001, en el reparto equitativo de las medidas productivas, que tendrán un mayor impacto directo sobre las economías y las no productivas con un impacto directo sobre la calidad de vida, en la participación de todas las administraciones y gran número de colectivos sociales y económicos (se han creado numerosas asociaciones, mesas sectoriales, cooperativas, voluntariados o centros de formación que han servido para generar y consolidar el tejido asociativo de los territorios); y en la consecución de inversiones de la iniciativa privada en municipios muy pequeños, con menos de 2.000 habitantes, que sin estas ayudas habría sido imposible realizar.

Estas políticas no deben orientar su impacto solamente en los efectos sobre el desarrollo económico del mundo rural, por su escasos recursos financieros, al ser insignificantes si además se comparan con otras políticas agrarias y rurales, sino por su carácter territorial debido a que la ejecución y gestión de este modelo de desarrollo va a estar confiado a los Grupos de Acción Local que podrán adaptar estas inversiones a las especificidades territoriales de los diferentes espacios. De hecho, en el nuevo periodo de programación, 2014 - 2020, no solo se habla de desarrollo rural, sino de desarrollo rural territorial, haciendo énfasis en las necesidades de la población del territorio sobre el que se actúa con estas ayudas y en los sectores más consolidados en los mismos. Se han financiado proyectos que han contribuido al fortalecimiento y creación de empresas dedicadas a la comercialización de productos locales, mejora y consolidación de industrias agroalimentarias (cárnicas, quesería, aceite, repostería, etc..), recuperación de oficios perdidos en el sector artesanal, la introducción de las nuevas tecnologías, el respeto al medio ambiente y la identificación de nuevos yacimientos de empleo. Se ha reforzado la oferta turística con la creación de un modelo de explotación a nivel de comarcas con asociaciones turísticas, marcas corporativas, centrales de reservas o rutas turísticas.

Dentro de este estudio, una de las conclusiones que queremos destacar es que el apoyo europeo y de las distintas administraciones al método LEADER todavía es claramente insu- 
ficiente. Se debería, en el siguiente período de financiación europea (2014-2020), aumentar los recursos e ir ampliando las medidas de actuación de los Grupos de Acción Local. Ha sido un avance que en el último período, FEADER, hayan gestionado los recursos de los ejes 3 y 4 y una submedida del eje 1, pero todavía resultan escasos para conseguir sus objetivos. Estos Programas deberían ampliar su gestión a medidas orientadas también al desarrollo del sector agrario (como las del Eje 1 del FEADER) ya que es todavía un sector primordial en la estructura productiva de la región y con una débil productividad, excesiva dependencia de las subvenciones de la PAC y del PER y unas explotaciones todavía poco rentables (excepto en algunas zonas del regadío o tierras de vid y secano, son mayoritariamente explotaciones extensivas agroganaderas y poco modernizadas). En el nuevo Reglamento (UE) $\mathrm{n}^{\circ}$ 1305/2013 del Parlamento Europeo y del Consejo de 17 de diciembre de 2013 relativo a la ayuda al desarrollo rural a través del Fondo Europeo Agrícola de Desarrollo Rural (FEADER) se presenta como primordial la cooperación entre distintos sectores, destacando el agrario y el agroalimentario, por la importancia de éstos en el desarrollo de los territorios rurales.

Para finalizar, el Método LEADER ha contribuido a la fijación de la población rural por ser una ayuda en el incremento de sus rentas y mejora de su nivel de vida a través de una diversificación de actividades en este medio como han sido el aprovechamiento de los recursos endógenos, la conservación del patrimonio, la mejora de la calidad y comercialización de los productos y, que todavía podrían ser ampliadas y mejoradas.

\section{AGRADECIMIENTOS}

Agradecimientos a la Dirección General de Modernización e Innovación Tecnológica del Gobierno de Extremadura, por la concesión de la ayuda para la formación del personal investigador predoctoral, cofinanciada con fondos FSE, con la cual es posible la realización de este trabajo.

\section{REFERENCIAS}

CEJUDO, E. y NAVARRO, F. (2009): «La inversión en los programas de desarrollo rural. Su reparto territorial en la provincia de Granada». Anales de Geografía de la Universidad Complutense, 29, pp. 37-64.

ESPARCIA, J. (2004): «Políticas públicas en el medio rural: desarrollo rural. Contribución de los programas LEADER y PRODER al desarrollo rural en España». Molinero, F., Majoral, R., Bartolomé, J.M., García Fernández, G., (coords.). Atlas de la España Rural. pp. 380-384.

ESPARCIA, J. (2014): «Innovation and networks in rural areas. An analysis from European innovative projects». Journal of Rural Studies. Elsevier. N ${ }^{\circ} 34$, pp. 1 - 14. Disponible en: http://www.sciencedirect.com/science/article/pii/S0743016713000995

DARGAN, L., SHUCKSMITH, M. (2008). «LEADER and innovation». Sociologia Ruralis. $\mathrm{N}^{\mathrm{o}}$ 48. Disponible en http://onlinelibrary.wiley.com/doi/10.1111/j.14679523.2008.00463.x/full. 
DAX, T., STRAHL, W., KIRWAN, J. y MAYE, D (2013): «The Leader programme 20072013: Enabling or disabling social innovation and neo-endogenous development? Insights from Austria and Ireland». European Urban and Regional Studies. Disponible en http://eur.sagepub.com/content/early/2013/07/25/0969776413490425.

GONZÁLEZ, J. (Dir.) (2006): «Desarrollo rural de base territorial: Extremadura (España). pp. 15-90.

MÁRQUEZ, D. 1999. «Estrategias de desarrollo turístico en Extremadura al amparo de la iniciativa Leader». En Actas del XV Congreso de Geógrafos Españoles. AGE. Departamento de Geografía. Universidad de Málaga.

MÁRQUEZ, D., FORONDA, C., GALINDO, L. y GARCÍA, A (2005). «Eficacia y eficiencia de Leader II en Andalucía. Aproximación a un índice-resultado en materia de turismo rural», Geographicalia, n 47, pp. 137-142.

MONDÉJAR, J., MONSALVE, F. y VARGAS, M., (2007): «Una propuesta de evaluación del impacto de los programas de desarrollo rural LEADER y PRODER»; Ager, Revista de estudios sobre despoblación y desarrollo rural, $\mathrm{n}^{\circ}$ 6, pp. 161-180.

NAVARRO, F., CEJUDO, E. y MAROTO, J.C. (2012): «Aportaciones a la evaluación de los programas de desarrollo rural», Boletín de la Asociación de Geógrafos Españoles, n ${ }^{\circ} 58$, pp. 349-380.

NIETO, A. y GURRÍA, J.L. (2008): «Las políticas rurales europeas y su impacto en Extremadura». Boletín de la Asociación de Geógrafos Españoles, nº 48, p. 225-246.

NIETO, A. y GURRÍA, J.L. (2010): «El modelo rural y el impacto de los programas LEADER y PRODER en Extremadura (Propuesta metodológica)». Scripta Nova. Revista Electrónica de Geografía y Ciencias Sociales. Barcelona: Universidad de Barcelona, vol. XIV, $\mathrm{n}^{\circ}$ 340. Disponible en: http://www.ub.edu/geocrit/sn/sn-340.htm.

NOGUERA, J., PÉREZ, J., VALERO, E. y FERRANDIS, A. (2009): «Un sistema de indicadores para la evaluación del desarrollo local. El caso de Cullera Impuls». XXXIV Congreso de la Asociación Española de Ciencia Regional. Valencia.

OCDE. (2004): Placed-based policies for rural development Extremadura, Spain (case study). 6th Session held at the OECD Headquarters in Paris on 7 December 2004.

PAPADOPOULOU, E., HASANAGAS, N. y HARVEY, D. (2011). «Analysis of rural development policy networks in Greece: Is LEADER really different?» Land Use Policy. $\mathrm{n}^{\circ}$ 28. Issue: 4. Disponible en http://www.sciencedirect.com/science/article/pii/ S026483771000116X.

PILLET, F. (2008): «Del turismo rural a la plurifuncionalidad en los territorios LEADER y PRODER de Castilla-La Mancha», en Cebrián, F. (Coord.). Turismo rural y desarrollo local. Cuenca, Universidad de Castilla-La Mancha, pp. 187-198.

Reglamento (CE) n 1698/2005 del Consejo, de 20 de septiembre de 2005, relativo a la ayuda al desarrollo rural a través del Fondo Europeo Agrícola de Desarrollo Rural (FEADER).

Reglamento (UE) n 1305/2013 DEL PARLAMENTO EUROPEO Y DEL CONSEJO de 17 de diciembre de 2013 relativo a la ayuda al desarrollo rural a través del Fondo Europeo Agrícola de Desarrollo Rural (FEADER) y por el que se deroga el Reglamento (CE) n o 1698/2005 del Consejo.

RUIZ, E., FRUTOS, M.L y CLIMENT, E. (2000).»La Iniciativa Comunitaria LEADER II y el Desarrollo Rural: el caso de Aragón». Geographicalia, nº 38, pp. 71-84. 
Red Extremeña de Desarrollo Rural (Redex). Disponible en: http://www.redex.org/ SANCHO, J. (1999): «Las claves del nuevo marco de desarrollo rural». Actualidad Leader: Revista de desarrollo rural, $\mathrm{n}^{\circ} 8$, pp. 8-9. 